Special Issue of the 6th International Congress \& Exhibition (APMAS2016), Maslak, Istanbul, Turkey, June 1-3, 2016

\title{
A Statistical Forecasting of Mechanical Properties of Mg-Ca Alloys Using Taguchi Design
}

\author{
L. Feray Guleryuz ${ }^{a *}$, R. IpeK ${ }^{a}$, I. Aritman ${ }^{b}$ And S. Karaoglu ${ }^{a}$ \\ ${ }^{a}$ Ege University, Bornova, Izmir, 35100, Turkey \\ ${ }^{b}$ Dokuz Eylul University, Izmir, 35370, Turkey
}

\begin{abstract}
In this study statistical Taguchi design was used to predict mechanical properties of biodegradable magnesium calcium composites, produced by powder metallurgy method. Results of analysis of variance (ANOVA) and regression analysis indicate the good accuracy of the model. Resulting microstructure and compression test behavior of the Mg-based alloys were studied. Visual inspection using scanning electron microscope analysis indicates that the microstructure of the composite is also greatly affected by these parameters. In addition, energy dispersive $\mathrm{X}$-ray spectroscopy analysis was performed for reliable determination of the chemical composition of the samples.
\end{abstract}

DOI: 10.12693/APhysPolA.131.592

PACS/topics: Biodegradable Mg, Taguchi

\section{Introduction}

It is a fact that technological development depends on advances in the field of material science. Recently, biomaterials have been widely investigated and applied. Biomaterials can be implanted to replace or repair missing tissue. Biodegradable metals (BMs) have wide usage in cardiovascular interventional devices and orthopedic implants due to combination of there perfect biocompatibility and degradability. Furthermore, as a class of biomedical metallic materials with the good mechanical properties, BMs have attracted the greatest interest [1-3].

Magnesium alloys have been also widely used in medical devices, such as stents, plates, screws and pins, as well as in orthopedic applications, due to their mechanical properties, comparable to natural bone, good biocompatibility and biodegradability [4]. However, pure $\mathrm{Mg}$ may corrode too early in the physiological $\mathrm{pH}$ environment (7.4-7.6), thus losing mechanical integrity before the tissue has sufficiently enhanced and producing hydrogen gas in the corrosion process [5-7].

Calcium is also a very important element in the human body [8]. As an important alloying element, Ca has been investigated in $\mathrm{Mg}$ alloys, although only a small amount of $\mathrm{Ca}$, around 1 at.\%, is soluble in $\mathrm{Mg}$.

The superior properties of $\mathrm{Mg}-\mathrm{Ca}$ alloy have been already reported [9]. In the present study, compression tests were conducted for these $\mathrm{Mg}-\mathrm{Ca}$ alloys to evaluate their mechanical properties. As a result the possibility of the development of $\mathrm{Mg}$ - and Ca-based intermetallic compounds, as new biodegradable implant materials, were discussed.

\section{Experimental work}

$\mathrm{Mg}$ was used as the base powder and was alloyed with 3 wt.\% of Ca. The magnesium powders were purcha-

*corresponding author; e-mail: ferayguleryuz@hotmail.com sed from Magnesium Metal company in Istanbul, Turkey. A mixture of elemental magnesium powder $(99.00 \%$ purity) and calcium powder (99.98\% purity) was mechanically milled at room temperature, using a high-energy planetary mill, under argon atmosphere. $\mathrm{Mg}$ and Ca powders were irregularly shaped. The average particle size of elemental $\mathrm{Mg}$ and Ca powders was $75 \mu \mathrm{m}$.

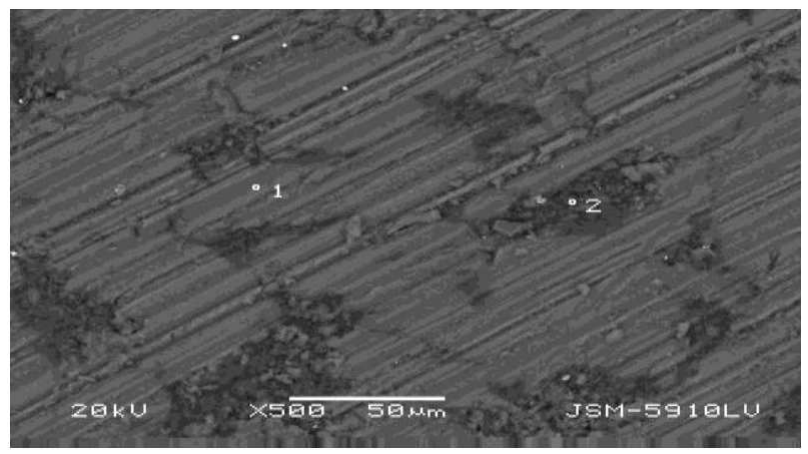

Fig. 1. Mg-Ca sample SEM image.

The powders were planetary ball milled using $10 \mathrm{~mm}$ diameter stainless steel balls with weight ratio of 10:1 and rotation speed of $250 \mathrm{rpm}$, for $18 \mathrm{~h}$. Then, high-strenght graphite die with $10 \mathrm{~mm}$ inner diameter and height of $60 \mathrm{~mm}$ was used for sintering of samples. The ball milled powders were put into the graphite die and hot press sintered under pressure of $20 \mathrm{Mpa}, 25 \mathrm{Mpa}$ and $30 \mathrm{Mpa}$, in argon atmosphere. Various values of pressure, sintering temperature and holding time were used. Sintering time was $20 \mathrm{~min}, 25 \mathrm{~min}$ and $30 \mathrm{~min}$. Sintering was followed by furnace cooling. Sintering temperature was $450^{\circ} \mathrm{C}$, $500^{\circ} \mathrm{C}$ and $550^{\circ} \mathrm{C}$.

Standard metallographic techniques were employed for preparing samples for micro-structural examination. Metallographic samples were prepared from the widthwise cross-sections of the investigated composites. All samples were gently grinded. The images were obtained by 
using Jeol Trade JSM 5910 scanning electron microscope (SEM). Backscattered electrons were used to obtain SEM images.
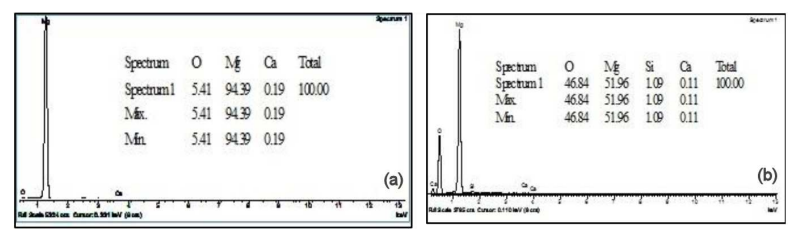

Fig. 2. (a) EDS pattern for. $\mathrm{Mg}-3$ wt.\% Ca, at point 1 in Fig. 1, (b) EDS pattern for. Mg-3 wt.\% Ca, at point 2 in Fig. 1.

Oxford Inca 7274 energy dispersive X-ray spectrometer (EDS) was used to identify phases present in the samples. Figure 1 shows the microstructure of the chosen sample. EDS has revealed that all produced composites contained oxygen, magnesium and calcium. Figure 2 presents the EDS results, obtained at point one and point two, marked in Fig. 1. The peaks were attributed to magnesium and oxygen. The corresponding phase has occurred due to the chemical activity of matrix and reinforcement compound, during the sintering process.

\subsection{Statistical design and data analysis}

Statistical design of experiments has been increasingly used by researchers and engineers for optimization of experiment. A combination of the levels of the parameters, which induce given optimum response, can also be located through this approach.

In this study, temperature, pressure and sintering time of $\mathrm{Mg}$ with 3 wt.\% of Ca were used as the main parameters in Taguchi factorial design. Totally nine experiments were performed for each group of samples. Table I shows the experimental design and results of experiments.

TABLE I

Experimental design and results of experiments.

\begin{tabular}{c|c|c|c|c|c|c|c|c|c}
\hline \hline Temperature (A) & Pressure (B) & Time (C) & Ultimate strength & Source & DF & Adj SS & Adj MS & $F$-value & $P$-value \\
\hline 450 & 45 & 20 & 15.8967 & A & 2 & 631.32 & 315.661 & 3246.42 & 0.000 \\
450 & 50 & 25 & 18.8947 & C & 2 & 26.77 & 13.385 & 137.66 & 0.007 \\
450 & 55 & 30 & 35.4384 & B & 2 & 438.25 & 219.127 & 2253.62 & 0.000 \\
500 & 45 & 25 & 26.5550 & Error & 2 & 0.19 & 0.097 & & \\
500 & 50 & 30 & 34.0695 & Total & 8 & 1096.54 & & & \\
500 & 55 & 20 & 42.8927 & & & & & & \\
550 & 45 & 30 & 39.6210 & & & & & & \\
550 & 50 & 20 & 39.6210 & & & & & & \\
550 & 55 & 25 & 52.4635 & & & & & &
\end{tabular}

TABLE II

Data set.

\begin{tabular}{c|c|c|c|c|c|c|c|c|c|c|c}
\hline \hline A & N & Mean & Grup & C & N & Mean & Grup & B & N & Mean & Grup \\
\hline 550 & 3 & 439018 & A & 30 & 3 & 363763 & A & 55 & 3 & 435982 & A \\
500 & 3 & 345057 & B & 20 & 3 & 328035 & B & 50 & 3 & 308617 & B \\
450 & 3 & 234099 & C & 25 & 3 & 326377 & C & 45 & 3 & 273576 & C
\end{tabular}

Values of "Prob $>$ F" less than 0.0500 indicate that model terms were significant. In this case, the temperature, pressure and sintering time were the significant model terms. The value of $R^{2}$ was 0.9998 . This shows that the percentage of the variability explained by the model was $99.98 \%$ and thus, the design was a good fit to the model. A high value of predicted $R^{2}$ (99.64) indicates that the model could satisfactorily predict the variability in the new data. The "Pred. $R$-squared" of 0.9964 was in reasonable agreement with the "Adj. $R$-squared" of 0.9993 . The following regression equation was established:

$$
\begin{aligned}
& \text { regression }=33.939-10.529 A_{450}+0.567 A_{500} \\
& \quad+9.963 A_{550}-1.136 C_{20}-1.301 C_{25}+2.437 C_{30} \\
& \quad-6.582 B_{45}-3.077 B_{50}+9.659 B_{55} .
\end{aligned}
$$

According to Tukey test for temperature, means for A, $\mathrm{B}$ and $\mathrm{C}$ groups had been obtained. We aim to reach the highest value, so temperature of 550, time of 30 and pressure of 55, which indicated Group A, were better, as shown in Table II. 


\section{Model adequacy}

Assumption of normality does not seem to be violated, since the data appear to fall along a straight line (Fig. 3, the first plot). Considering the constant variance, no serious departure from assumption of constant variance was observed. This was evident by the random pattern of the residuals. There was no noticeable pattern (like outward or inward funnel). This indicates that the constant variance assumption was also reasonable (Fig. 3 the second plot). Considering the independence, from the plot it was observed that residuals were randomly scattered. It shows no obvious pattern, which means that our model passes the assumption of independence (Fig. 3 the last graph).

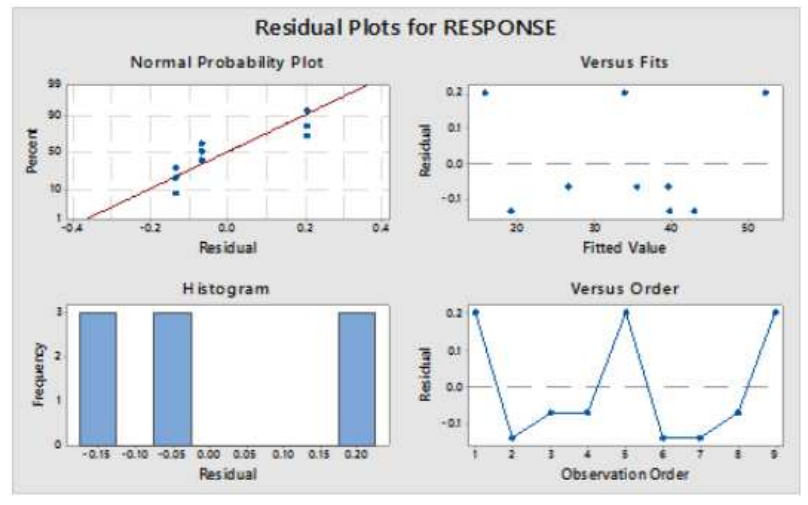

Fig. 3. Residual plots for adequacy checking.

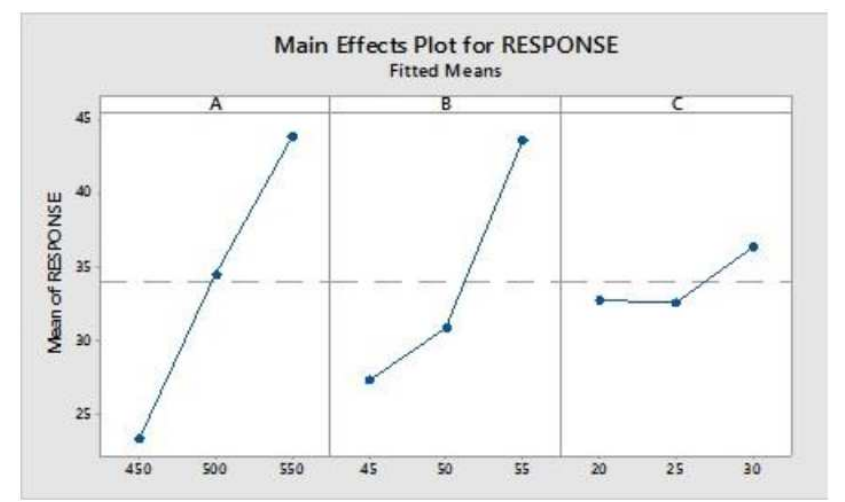

Fig. 4. Main effect plots for the ultimate strength.

When pressure was at low level, the ultimate strength of 27 units was reached and if the pressure was at high level, the ultimate strength was roughly 45 units. The higher level of the factor was adequate for the model due to the aim of maximization (the second plot in Fig. 3). When time value was small, the ultimate strength was smaller. When time was at mid-level, the strength of the material was also at mid-level. Besides, according to the graph, low and mid-points of the factors had approximately the same effect on the results. And lastly, if time was at high level, the ultimate strength was higher (the third plot in Fig. 3.)

\subsection{Main effect plots}

When temperature was at low level, the ultimate strength was lower. In this case we aim to maximize the strengthens of the material, as well. When temperature was at mid-level, the strength of the material was also at mid-level. And lastly, if temperature was at high level, the ultimate strength was higher (the first plot in Fig. 4).

When pressure was at low level, the ultimate strength of 27 units was reached. If the pressure was at high level, the ultimate strength was roughly 45 units. The higher level of the factor was adequate for the model due to the aim of maximization (the second plot in Fig. 4).

When time was at low level, the ultimate strength was lower, and we aim to maximize the strength of the material, as well. When time was at mid-level, the strength of the material was at mid-level. Besides this, according to the graph, low and mid-points of the factors have approximately the same effect on the results. And lastly, if time was at high level, the ultimate strength was higher (the third graph in Fig. 4).

\section{Conclusions}

A confident statistical model, based on Taguchi experiment design, had been developed, which can be used for the optimization of $\mathrm{Mg}-\mathrm{Ca}$ alloy, produced by mechanical alloying, followed by Tukey HSD post test. Results show that when temperature, pressure and sintering time was at low level the ultimate strength was lower. All other parameters and constant value were statistically significant at level of 0.05 .

\section{References}

[1] Y.F. Zheng, X.N. Gu, F. Witte, Mater. Sci. Eng. R 77, 1 (2014).

[2] L.L. Tan, X.M. Yu, P. Wan, K. Yang, J. Mater. Sci. Technol. 29, 503 (2013).

[3] M. Moravej, D. Mantovani, Int. J. Mol. Sci. 12, 4250 (2011).

[4] F. Witte, Acta Biomater. 6, 1680 (2010).

[5] F. Witte, V. Kaese, H. Haferkamp, E. Switzer, A. Meyer-Lindenberg, C.J. Wirth, H. Windhagen, Biomaterials 26, 3557 (2005).

[6] M.P. Staiger, A.M. Pietak, J. Huadmai, G. Dias, Biomaterials 27, 1728 (2006).

[7] C. Wen, Y. Yamada, K. Shimojima, Y. Chino, H. Hosokawa, M. Mabuchi, Mater. Sci. Forum 419-422, 1001 (2003).

[8] S.N. Nayab, F.H. Jones, I. Olsen, Biomaterials 28, 38 (2007).

[9] Z. Li, X. Gu, S. Lou, Y. Zheng, Biomaterials 29, 1329 (2008). 